\title{
Process-based analysis of terrestrial carbon flux predictability
}

\author{
István Dunkl $^{1,2}$, Aaron Spring ${ }^{1}$, Pierre Friedlingstein ${ }^{3}$, and Victor Brovkin ${ }^{1,4}$ \\ ${ }^{1}$ Max Planck Institute for Meteorology, Hamburg, Germany \\ ${ }^{2}$ International Max Planck Research School on Earth System Modelling, Hamburg, Germany \\ ${ }^{3}$ College of Engineering, Mathematics and Physical Sciences, University of Exeter, Exeter, UK \\ ${ }^{4}$ Center for Earth System Research and Sustainability, University of Hamburg, Hamburg, Germany
}

Correspondence: István Dunkl (istvan.dunkl@mpimet.mpg.de)

Received: 3 June 2021 - Discussion started: 10 June 2021

Revised: 24 September 2021 - Accepted: 4 October 2021 - Published: 2 December 2021

\begin{abstract}
Despite efforts to decrease the discrepancy between simulated and observed terrestrial carbon fluxes, the uncertainty in trends and patterns of the land carbon fluxes remains high. This difficulty raises the question of the extent to which the terrestrial carbon cycle is predictable and which processes explain the predictability. Here, the perfect model approach is used to assess the potential predictability of net primary production (NPPpred) and heterotrophic respiration (Rhpred) by using ensemble simulations conducted with the Max Planck Institute Earth system model. In order to assess the role of local carbon flux predictability (CFpred) in the predictability of the global carbon cycle, we suggest a new predictability metric weighted by the amplitude of the flux anomalies. Regression analysis is used to determine the contribution of the predictability of different environmental drivers to NPPpred and Rhpred (soil moisture, air temperature, and radiation for NPP, and soil organic carbon, air temperature, and precipitation for $\mathrm{Rh}$ ). Global NPPpred is driven to $62 \%$ and $30 \%$ by the predictability of soil moisture and temperature, respectively. Global Rhpred is driven to $52 \%$ and $27 \%$ by the predictability of soil organic carbon and temperature, respectively. The decomposition of predictability shows that the relatively high Rhpred compared to NPPpred is due to the generally high predictability of soil organic carbon. The seasonality in NPPpred and Rhpred patterns can be explained by the change in limiting factors over the wet and dry months. Consequently, CFpred is controlled by the predictability of the currently limiting environmental factor. Differences in CFpred between ensemble simulations can be attributed to the occurrence of wet and dry years, which influences the predictability of soil moisture and temperature. This variability of predictability is caused by the state dependency of ecosystem processes. Our results reveal the crucial regions and ecosystem processes to be considered when initializing a carbon prediction system.
\end{abstract}

\section{Introduction}

As a net sink for atmospheric $\mathrm{CO}_{2}$, terrestrial ecosystems absorb around one-third of the anthropogenic emissions (Friedlingstein et al., 2020). Carbon fluxes between the landatmosphere interface have a high interannual variability with a standard deviation (SD) of $0.7 \mathrm{PgC} \mathrm{yr}^{-1}$ (Sitch et al., 2015) and cause the majority of the atmospheric $\mathrm{CO}_{2}$ fluctuations (Ciais et al., 2013; Spring et al., 2020). The high variability of terrestrial carbon fluxes can be attributed to the sensitivity of land surface processes to climatic drivers; however the relative importance of temperature and precipitation are still debated (Jones et al., 2001; Beer et al., 2010; Bloom et al., 2016; Fang et al., 2017; Jung et al., 2017; Bastos et al., 2018). In accordance with the limited understanding of carbon flux variability, models are not able to fully reproduce the spatiotemporal patterns of the terrestrial carbon cycle. This is reflected in the poor representation of soil organic carbon (SOC) in Earth system models (ESMs), the inability to adequately model gross primary production (GPP) from eddy covariance flux tower sites (Luo et al., 2015), and the dif- 
ficulty to detect the efforts taken in emission reduction due to internal variability of atmospheric $\mathrm{CO}_{2}$ variability (Spring et al., 2020). In order to produce more realistic predictions, efforts in model development have been directed towards using observations to constrain model parameters (Zeng et al., 2014; Bloom et al., 2016; Mystakidis et al., 2016; Chadburn et al., 2017; Tziolas et al., 2020) and to refine model structure to incorporate more processes and interactions (Krull et al., 2003; Stockmann et al., 2013; Xu et al., 2014; Luo et al., 2016). While efforts in model development are continuing to narrow the gap between the simulated and observed carbon cycle, the lack of progress in improving the predictive ability of the models raises the question of the extent to which the terrestrial carbon cycle is predictable at all (Luo et al., 2015). The potential predictability of a system can be estimated by using the perfect model framework. Ensemble simulations are initialized along a control run with each member of the ensemble having slightly perturbed initial conditions. The upper limits of predictability are then derived by analysing the divergence of the ensemble simulations. This method assumes (a) perfect model physics which are able to reproduce the full spectrum of natural variability and (b) perfect knowledge of the modelled system and a model whose representation of the real world is "perfect enough" (Boer et al., 2013). Séférian et al. (2018) used the perfect model framework to assess the potential predictability of terrestrial carbon fluxes (CFpred) at annual time steps. They estimated the predictive horizon of terrestrial carbon fluxes to be 2 years globally and up to 3 years in northern latitudes. The high variability of predictability among different initializations suggests a state dependence of CFpred, but no further mechanisms of predictability were investigated therein. Multiple processes can being regarded as the sources of CFpred. Due to the high sensitivity of the terrestrial carbon cycle to climate, climate predictability provides carbon fluxes with a basic prediction horizon. The main contributor to climate predictability is El Niño-Southern Oscillation (ENSO), which explains over $40 \%$ of the variability in global net primary production (NPP) (Bastos et al., 2013) and a large fraction of CFpred (Zeng et al., 2008). El Niño events are associated with high temperatures and low precipitation in the tropics which cause a reduction of the land carbon sink of $1.8 \mathrm{PgC} \mathrm{yr}^{-1}$ per $1{ }^{\circ} \mathrm{C}$ sea surface temperature (SST) anomaly in the Niño 3 region (Jones et al., 2001). This strong relationship between SST and the carbon cycle was used by Betts et al. (2016) to predict annual $\mathrm{CO}_{2}$ growth. Their statistical model uses the annual average SST in the Niño 3.4 region to successfully predict the $\mathrm{CO}_{2}$ rise with a precision of $0.53 \mathrm{ppm} \mathrm{yr}^{-1}$. Furthermore, Spring and Ilyina (2020) showed that ESM-based initialized predictions can predict atmospheric $\mathrm{CO}_{2}$ variations up to 3 years in advance.

However, CFpred is extended beyond the predictability of climate by slowly varying land surface processes that filter out the high-frequency noise of the climate signal. As the most prominent process, soil moisture memory is known to increase the predictability of temperature (TEMPpred) and precipitation (PRECIPpred) by several months (Chikamoto et al., 2015), but memory can also be attributed to phenology (Weiss et al., 2014) and SOC (Lovenduski et al., 2019). Besides the slowly changing land state variables, the memory is further extended through land-atmosphere coupling which propagates soil anomalies back to the atmosphere by energy and water fluxes (Bellucci et al., 2015).

Previous studies that focus on the mechanisms of CFpred investigated the role of various land processes and how they contribute to the overall CFpred. Weiss et al. (2014) found increased predictability of evaporation and to some extent temperature due to a dynamic simulation of leaf area index (LAI), which would also extend CFpred. The role of land surface initialization in CFpred was studied by Zeng et al. (2008) and Lovenduski et al. (2019). Zeng et al. (2008) isolated the fraction of CFpred which is based solely on initial conditions and compare fully coupled dynamic simulations with statistical models. Lovenduski et al. (2019) quantified the degree to which CFpred improves when the land surface is initialized. They also assessed the relative importance of the individual land surface processes for the variability of terrestrial carbon fluxes and found that CFpred depends on the correct initialization of vegetation carbon biomass and soil moisture rather than temperature. These studies have shown the significant advantage of dynamic forecasting systems, suggesting CFpred extends beyond the predictability of the forcing variables due to land surface processes. However, these studies were not focused on contributions of individual drivers of carbon fluxes to CFpred or on processes responsible for maintaining CFpred. Here, we use perfect model simulations conducted with an ESM to investigate the structure and mechanisms of the CFpred. Initialized ensemble simulations are created from a range of ENSO states. Analysed are the carbon fluxes with the highest contribution to the interannual variability of the land-atmosphere $\mathrm{CO}_{2}$ exchange. These are NPP with an interannual SD of $0.99 \mathrm{PgC} \mathrm{yr}^{-1}$ and heterotrophic respiration (Rh) with an SD of $0.29 \mathrm{PgC} \mathrm{yr}^{-1}$ (Wang et al., 2016). The potential predictability of NPP (NPPpred) and Rh (Rhpred) is derived from the rate of divergence within the ensemble members. We evaluate the predictability data to find how NPPpred and Rhpred differ in their spatiotemporal patterns and variability. Lastly, we identify the key drivers of NPP and $\mathrm{Rh}$ and determine their contribution to NPPpred and Rhpred. We use this framework to explain the attained spatiotemporal patterns of CFpred and identify the underlying land system processes producing these patterns.

\section{Methods}

\subsection{Earth system model}

This study is based on the output of the MPI-ESM version 1.2 developed for the Coupled Model Intercomparison Project 
6 (Mauritsen et al., 2019). The model runs fully coupled in the LR configuration that uses the atmospheric component ECHAM 6.3.05 with a T63 spatial truncation and 47 atmospheric layers. The atmospheric model is directly coupled with the land model JSBACH 3.20 and uses an interactive carbon cycle, which means atmospheric $\mathrm{CO}_{2}$ reacts to land and ocean carbon fluxes.

\subsection{Predictability metrics}

The control simulation used in this study is a 1000 -year unforced simulation with a preindustrial $\mathrm{CO}_{2}$ concentration of $285 \mathrm{ppm}$. A total of thirty-five 10-member ensemble simulations are initialized, each starting in January with a run time of 2 years. The unperturbed simulation of the control run is added to the ensembles as the 11th member. Initialization dates are selected manually in order to attain a diversity of ENSO states. The selected dates are grouped into three categories: El Niño, La Niña, or ENSO-neutral. The potential predictability is assessed by using a correlation-based and a distance-based metric. The anomaly correlation coefficient (ACC) is a commonly used metric to measure forecast skill (Jolliffe and Stephenson, 2012) which calculates the correlation between predicted and observed anomalies as

$\mathrm{ACC}_{j, t}=\frac{\operatorname{cov}(f, o)}{\sigma_{f} \cdot \sigma_{o}}$,

where $j$ and $t$ are grid cell and lead time, cov is the covariance, and $f$ and $o$ are the forecast and validation anomalies. Similar to Collins and Sinha (2003) and Becker et al. (2013), the noise in the ACC is reduced by averaging over several ACC values. This is achieved by taking all 11 ensemble members as the validation in turn, while the mean of the remaining ensemble members serves as the forecast. Although the ACC is an intuitive metric which is calculated from all initializations and thus provides a robust estimation of the predictability, it does not allow us to investigate the variability of predictability between initializations. The comparison of predictabilities between initialization is achieved by the use of a distance-based metric which is computed for all initializations individually. The distance-based metric used here is the normalized ensemble variance $(V(t))$ based on the method proposed by Griffies and Bryan (1997). Predictability is defined as the ensemble variance normalized by the variance of the climatology as

$V(t)=\frac{\frac{1}{M} \sum_{i=1}^{M}\left[X_{i}(t)-\bar{X}(t)\right]^{2}}{\sigma^{2}}$,

where $t$ is lead time, $M$ the number of ensemble members, $X_{i}$ the $i$ th member, $\bar{X}$ the ensemble mean, and $\sigma^{2}$ the variance of the control simulation. In this study, the complement of the normalized ensemble variance is used as $V_{\mathrm{c}}(t)=1-V(t)$. The resulting metric indicates perfect predictability at a value of 1 and an ensemble spread that exceeds the climatological variance for values below zero.

While ACC and $V_{\mathrm{c}}$ allow the estimation of regional predictability, these metrics are not suitable to evaluate the impact of local predictabilities on the predictability of the global carbon cycle. This is due to the disregard of the flux amplitude in the calculation of the metrics. Both of the metrics are prone to producing above-average predictabilities in regions where carbon fluxes are generally low or even close to zero, such as subtropical deserts. Here we propose a weighted predictability metric that allows us to assess local predictabilities with regard to their impact on the predictability of the global carbon cycle. $V_{\mathrm{c}}$ is weighted by using an approach similar to risk assessment, which is calculated as the product of likelihood and impact. Here a weighted predictability $w V_{\mathrm{c}}$ is calculated by multiplying $V_{\mathrm{c}}$ with the absolute carbon flux anomaly of the ensemble mean:

$w V_{\mathrm{c}}(t)=V_{\mathrm{c}}(t) \times|\Delta \operatorname{FLUX}(t)|$.

\subsection{Decomposition of predictability}

In order to investigate the drivers of CFpred, the $V_{\mathrm{c}}$ of NPP and $\mathrm{Rh}$ are decomposed into components contributing to the predictability of these fluxes similar to an approach used by Jung et al. (2017). They used regression analysis to determine the contribution of environmental variables to the anomalies in GPP and ecosystem respiration. Here the assumptions of Jung et al. (2017) are extended from carbon flux anomalies to CFpred: a high CFpred needs to be caused by a high predictability of one or more of its driving environmental variables. Using this assumption, NPPpred and Rhpred are modelled as the response to the predictability of the individual environmental drivers. Regression analysis is used to determine the contribution of the predictability of the environmental variables to NPPpred and Rhpred. The drivers of NPPpred are selected following the drivers of GPP in Jung et al. (2017) as two layers of soil moisture (midSOILpred for $19-78 \mathrm{~cm}$ depth and deepSOILpred for 79-268 cm depth), air temperature (TEMPpred), and photosynthetically active radiation (PARpred). The drivers of Rhpred are based on the rate modifying factors used in JSBACH to calculate Rh, which are TEMPpred, PRECIPpred, and SOCpred. Although precipitation has no direct relationship with $\mathrm{Rh}$, the $\mathrm{Rh}$ submodel used in JSBACH is parameterized using precipitation because of its strong relationship with moisture in the uppermost soil layer where most of the respiration takes place. Instead of SOC, the content of the aboveground acid-hydrolysable carbon pool (here referred to as SOC) is used as a surrogate variable. The contribution of the predictability of the environmental drivers to the CFpred is calculated as

$V_{\mathrm{c}} \operatorname{FLUX}_{j, t, i}=\sum_{k}\left[a_{j, t}^{\mathrm{DRI}_{k}} \times V_{\mathrm{c}} \mathrm{DRI}_{k, j, t, i}\right]+\epsilon_{j, t, i}$,

with $V_{\mathrm{c}}$ FLUX being the complementary normalized ensemble variance of NPP or Rh, $a^{\mathrm{DRI}_{k}}$ the coefficient of the $k$ th 
(a)

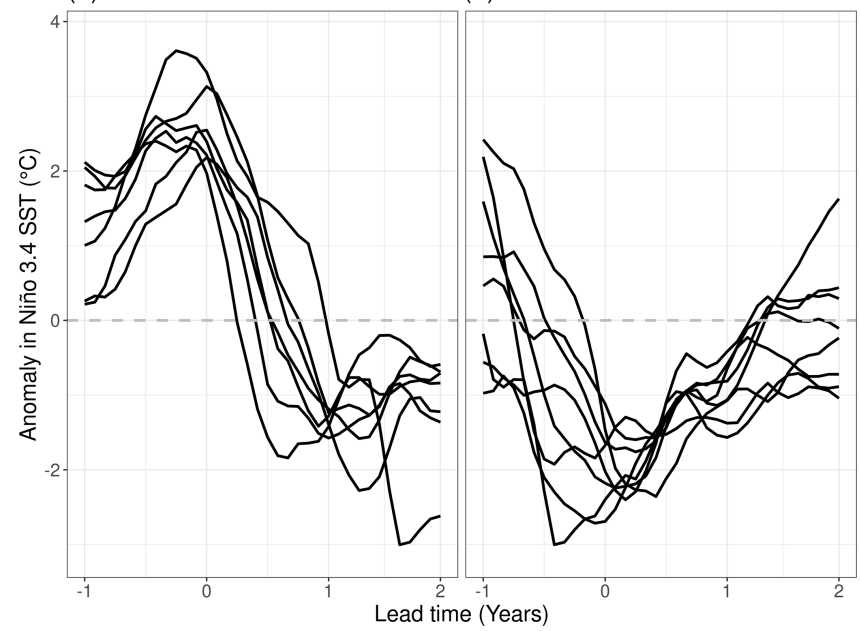

Figure 1. Three-month running mean SST anomaly in the Niño 3.4 region of (a) seven El Niño and (b) eight La Niña simulations. Simulations are initialized at lead time 0 and run for 24 months. Lines show the Niño 3.4 SST of the control simulation.

driver (for example TEMPpred), $V_{\mathrm{c}}$ DRI the predictability of the $k$ th driver, and $\epsilon$ the residual error term. Grid cell, lead time, and initialization are denoted by the indices $j, t$, and $i$. The regression coefficients are calculated by using nonnegative least squares (Mullen and van Stokkum, 2012) for every grid cell and lead time by using the data from all initializations. After fitting the regression model to the data, the individual components of CFpred are calculated as

$V_{\mathrm{c}} \mathrm{FLUX}_{i, t, s}^{\mathrm{DRI}_{k}}=a_{i, t}^{\mathrm{DRI}_{k}} \times V_{\mathrm{c}} \mathrm{DRI}_{k, i, t, s}$,

where $V_{\mathrm{c}} \mathrm{FLUX}^{\mathrm{DRI}}$ describes the amount of predictability of FLUX that can be attributed to the driver $k$.

\section{Results and discussion}

Out of the 35 ensemble simulations initialized along the control run, 7 simulations are part of the El Niño and 8 simulations are part of the La Niña group (Fig. 1). The El Niño simulations peak between the September before initialization and January with peak values between 2.2 and $3.6^{\circ} \mathrm{C}$ (3-month running mean Niño 3.4 SST anomaly). They show a fast decline in the anomaly with most models having a negative anomaly in December of the first year and evolving into a La Niña event in the second year. Peaks of the La Niña simulations fall between September and June and, while their relative peak anomalies are smaller $\left(-1.6\right.$ to $\left.3.0^{\circ} \mathrm{C}\right)$, the negative anomaly can be sustained well into the second year.

\subsection{Potential predictability}

The 35 perfect model simulations are used to assess potential NPPpred and Rhpred. Zonal means of the ACC are shown in

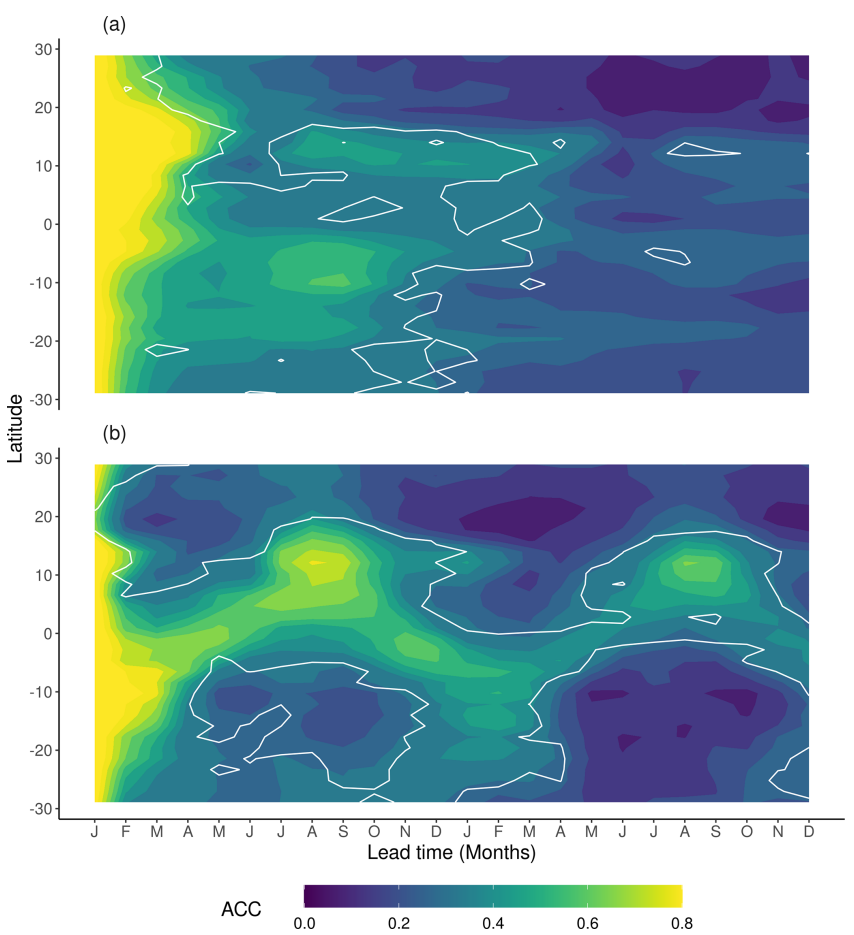

Figure 2. Zonal means of ACC derived from 35 ensemble simulations starting in January for (a) NPP and (b) Rh. Contour lines indicate correlations above the $95 \%$ confidence level.

Fig. 2 (zonal plots of predictability are limited to $30^{\circ} \mathrm{S}$ to $30^{\circ} \mathrm{N}$ to highlight the areas of high predictability). NPPpred and Rhpred are highest in the tropics between $20^{\circ} \mathrm{N}$ and S, where carbon fluxes are at their global maximum. However, apart from the generally high predictability in the tropics, the patterns of NPPpred and Rhpred differ in several aspects. While the ACC of NPP has a slower temporal decline with values above 0.8 for 2 to 3 months around the Equator, the ACC of Rh drops below 0.5 within the first 2 months for most latitudes. However, Rh shows much higher long-term predictability, especially in the second year of the simulation where Rhpred is much higher than NPPpred.

While both predictability patterns show signs of a seasonal cycle, they are out of phase, with Rhpred distinctly following the wet season and NPPpred appearing to be higher in the dry seasons of the first year. This has a large role in the comparability of NPPpred and Rhpred, since high NPPpred occurs at the time of the seasonal low of NPP fluxes, while high Rhpred is associated with the seasonal high. Another characteristic of the seasonal cycles is their continuity. Rhpred migrates continuously across the zones, while NPPpred demonstrates a sporadic behaviour with a high predictability at around $15^{\circ} \mathrm{N}$ in January to March and another one at $10^{\circ} \mathrm{S}$ from July to September.

The spatial patterns of ACC are shown in Fig. 3 for March, June, and September of the first year and September of the second year. Rhpred shows a very coherent pattern with a 


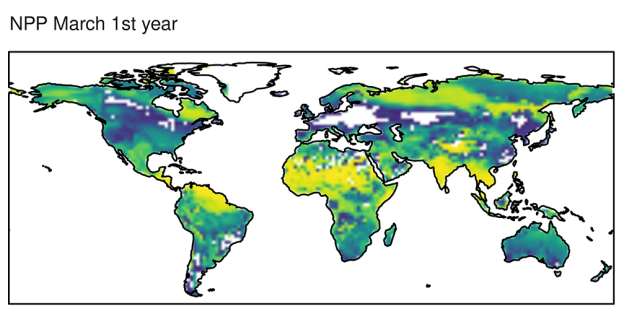

NPP June 1st year

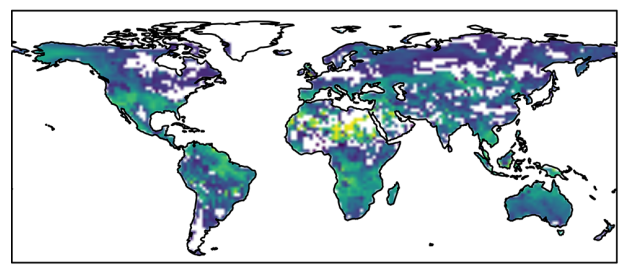

NPP September 1st year

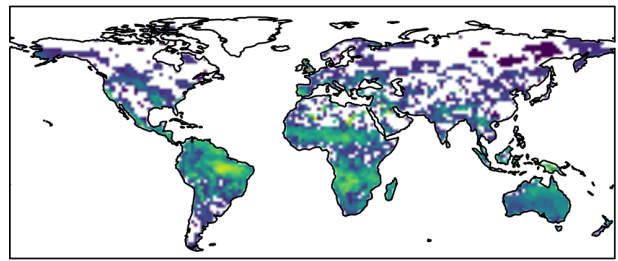

NPP September 2nd year

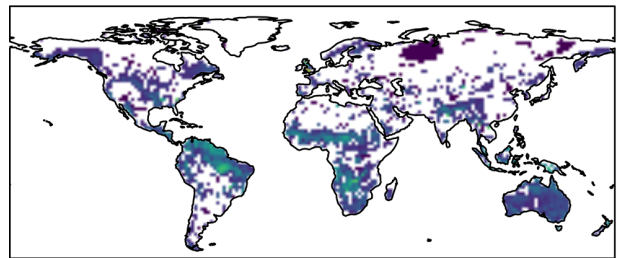

Rh March 1st year

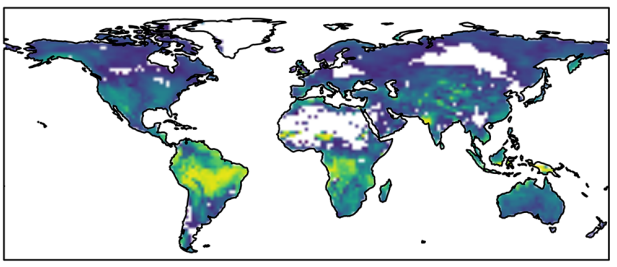

Rh June 1st year

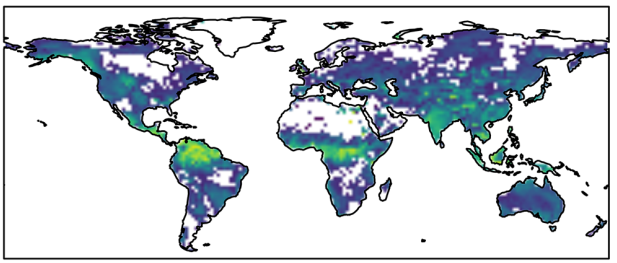

Rh September 1st year

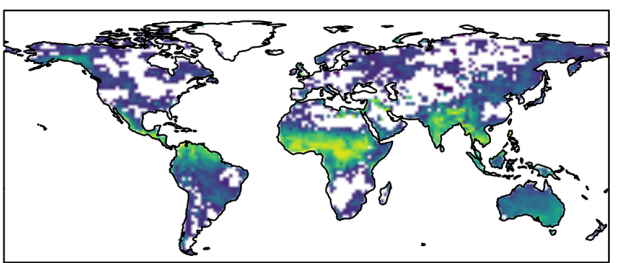

Rh September 2nd year

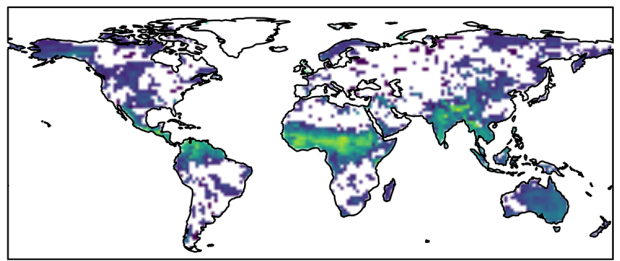

2.

ACC

Figure 3. ACC of NPP and Rh. The colour scale is cropped at zero. Only values above the $95 \%$ confidence interval are shown.

band of high predictability migrating from south to north across all continents. The patterns of NPPpred appear to be less constrained by latitude. Although March predictability is dominated by the northern tropics and subtropics, there are other high-predictability regions based on initial memory, especially at high latitudes. As opposed to Rhpred, there is no high-predictability band moving across the zones. Instead, NPPpred is re-emerging south of the Equator in September in the southern Amazon Basin, southern Africa, and Southeast Asia. An aberration from the seasonal pattern is in the Sahel, which has a relatively high NPPpred throughout both years, except in June and July (not shown).

A large portion of the high NPPpred areas can be attributed to predictability gained by ENSO. These high-predictability areas are concurring with the carbon flux anomalies caused by ENSO-related climate variability (Hashimoto et al., 2004; Bastos et al., 2013). A specific example of this is the disparity in NPPpred between the tropical rainforests of the Amazon and the Congo basins. It shows that the high NPPpred of the tropics is not an intrinsic property of these ecosystems. A reason for the relatively low NPPpred within the Congo Basin could be because it is not strongly impacted by ENSO (Holmgren et al., 2001). These findings highlight the importance of correctly simulating the ENSO process. Especially the localization of ENSO-related rainfall patterns is crucial, since they provide a sustained and predictable anomaly in water availability.

Many of the identified spatial patterns of CFpred can be discovered in similar studies. Most models agree on the Amazon Basin as the global hotspot of CFpred (Zeng et al., 2008; Ilyina et al., 2021), and some reflect the increased predictability in Southeast Asia and southern Africa (Zeng et al., 2008), but the comparison of predictability horizons remain difficult due to the use of different predictability metrics.

The results reveal different areas in which an operational NPP forecast can be used to increase food security. The high NPPpred of the Sahel and Kalahari savanna ecosystems (Fig. 3) could be used to plan stocking rates in order to avoid 
grassland degradation due to overgrazing in dry years (Tews et al., 2006). Other promising regions are northeast and central Brazil. The high NPPpred in these areas could be used to select crop varieties which are more or less drought tolerant depending on the given forecast.

\subsection{Composition of predictability}

CFpred is sufficiently captured by the regression models (Eq. 4) with a correlation of 0.71 and 0.75 for NPP and Rh, respectively (averaged correlation between the $V_{\mathrm{c}}$ derived from the ensemble simulations and the $V_{\mathrm{c}}$ of the regression model for each grid cell and lead time, not shown). The contributors of CFpred show strong spatiotemporal heterogeneity with drivers alternating across seasons and regions. The temporally averaged contributions to weighted predictability are shown in Fig. 4. The drivers of NPPpred are SOILpred (sum of midSOILpred and deepSOILpred) and TEMPpred, which explain $62 \%$ and $30 \%$ of the globally averaged NPPpred, respectively. PARpred only contributes $8 \%$ to the NPPpred, most of it in the first month of the simulations. The NPPpred patterns of $V_{\mathrm{c}}$ explained by SOILpred and TEMPpred are similar to the patterns of ACC, although areas with low carbon flux densities are excluded through weighting by absolute flux anomaly. While the NPPpred explained by SOILpred has a spatial extent that broadly covers all regions of high NPPpred, TEMPpred is concentrated in certain areas. TEMPpred is high in a band extending from the Amazon Basin to northern South America, in southern Africa, and in Southeast Asia. The largest contributor to Rhpred is SOCpred (52\%) followed by TEMPpred (27\%). Similar to NPPpred, the temperature component is highest in the Amazon Basin, southern Africa, and Southeast Asia.

In order to facilitate a system for operational NPP prediction, a network of sensors could be installed to gather data on the initial condition of the land surface. The patterns of the role of soil moisture in predicting NPP (Fig. 4) reveal the areas on which the efforts in establishing such a network should be focused to maximize the impact.

There are more variables that are regarded as key drivers of NPP variability and could have been regarded as predictors in the regression models. Most importantly, LAI and humidity play an important role in NPP variability (Schaefer et al., 2002). Several studies show the role of a dynamical simulation of LAI in extending the predictability of land surface processes (Zeng et al., 1999; Wang et al., 2010, 2011; Weiss et al., 2012, 2014). Here, the inclusion of LAI as a predictor is rejected because of the susceptibility of regression models to correlated predictors. The changing concentration of atmospheric $\mathrm{CO}_{2}$ is causing trends in NPP as global atmospheric levels are rising (Winkler et al., 2021); however, we assumed that the interannual variability of $\mathrm{CO}_{2}$ fertilization is below a meaningful contribution to overall variability. Although clay content plays a major role in carbon turnover rates in soil (Coleman et al., 1997), it is not considered in the JSBACH
Rh submodel (Tuomi et al., 2009) and was not included in this study.

\subsubsection{Seasonality}

The seasonal patterns of NPPpred revealed in the ACC data (Figs. 2 and 3) are reproducible by the decomposed predictability metric $V_{\mathrm{c}}$ (Fig. 5). They show the re-emergence of predictability in the dry season at various locations and reveal that this phenomenon cannot be attributed to a single factor. The largest pattern is a re-emergence in July to November at 1 to $4^{\circ} \mathrm{S}$, and this can be associated with the high NPPpred in the southern Amazon (Fig. 3, NPP September first year). This pattern is due to increased TEMPpred throughout the dry season, which is extended by high deepSOILpred in September, and even reoccurs in the second year of the simulation. Another pattern explains the high NPPpred in southern Africa between August and October, which is due to deepSOILpred.

These cases of high dry-season NPPpred in the tropics are most likely due to the seasonally changing limitations of NPP. During the productive wet season, plant growth is limited by incoming radiation (Wang et al., 2010), which has little variability and poor predictability. Instead, most of the interannual variability of NPP can be explained by dry-season variability. One study found over $80 \%$ of western Amazon NPP variability took place between July and September (Wang et al., 2011). The water limitation of NPP during the dry season (Tian et al., 2000) not only introduces higher variability as compared with the energy-limited wet season, but the coupling of NPP to soil moisture also lends NPP the high predictability of soil moisture.

Although the seasonality of Rhpred shows a reverse tendency to NPPpred with higher predictability in the wet season, the mechanisms explaining the seasonality are similar. The seasonally varying Rhpred can be explained by the inherently different predictability of the seasonally dominant limiting factor of Rh (Fig. 6). During the dry season the limiting factor of $\mathrm{Rh}$ is precipitation, which has a generally low predictability. The absence of precipitation for several weeks will inhibit soil respiration completely. There is a sharp increase in $\mathrm{Rh}$ variability in the dry-wet transition because the onset of precipitation is difficult to predict. As precipitation increases, the moisture constraint is asymptotically lifted and approaches zero. At this point, Rh becomes limited by substrate availability, which has a much higher predictability than climatic variables. The high SOCpred is due to the persistence of SOC anomalies because of the low decomposition rates and the pause of decomposition during dry seasons. Although TEMPpred is higher than PRECIPpred, it only plays a minor role in tropical Rhpred because tropical Rh has relatively low-temperature sensitivity (Meir et al., 2008).

These pronounced seasonal patterns of Rhpred hinge on the implementation of the precipitation sensibility function in MPI-ESM. The shape and parameterization of the rate 


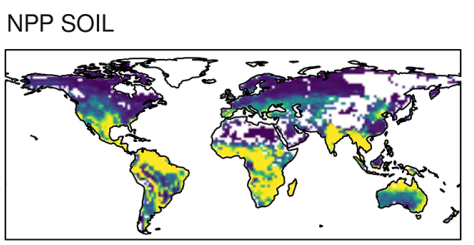

Rh SOC

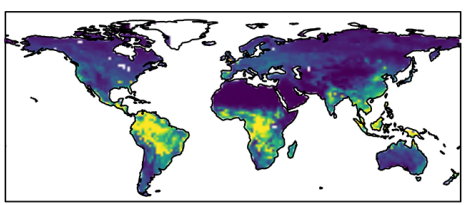

NPP TEMP

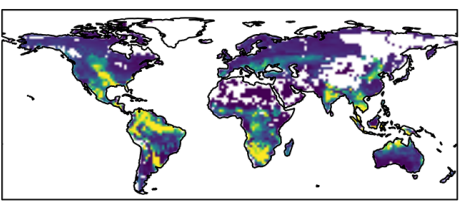

Rh TEMP

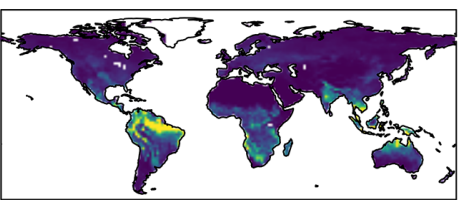

NPP PAR

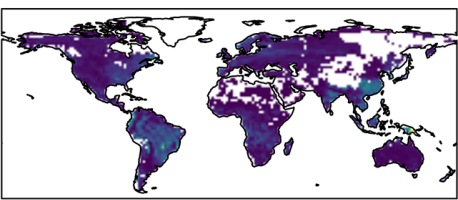

Rh PRECIP

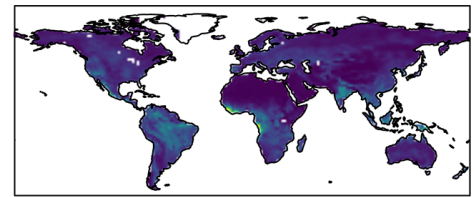

Weighted predictability $\left(\mathrm{g} \mathrm{C} \mathrm{m}^{-2}\right.$ month $\left.^{-1}\right)$

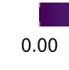

0.25

0.50

Figure 4. Contributing components to the weighted predictability $\left(w V_{\mathrm{c}}\right)$ of NPP and Rh. The contributors to NPP predictability are the predictability of soil moisture (SOIL), temperature (TEMP), and photosynthetically active radiation (PAR). Contributors to Rh predictability are the predictability of soil organic carbon (SOC), TEMP, and precipitation (PRECIP). The averaged predictability of the first 12 months lead time weighted by carbon flux anomaly of the ensemble means. The sum of all components of a flux type give the modelled total predictability of that flux.

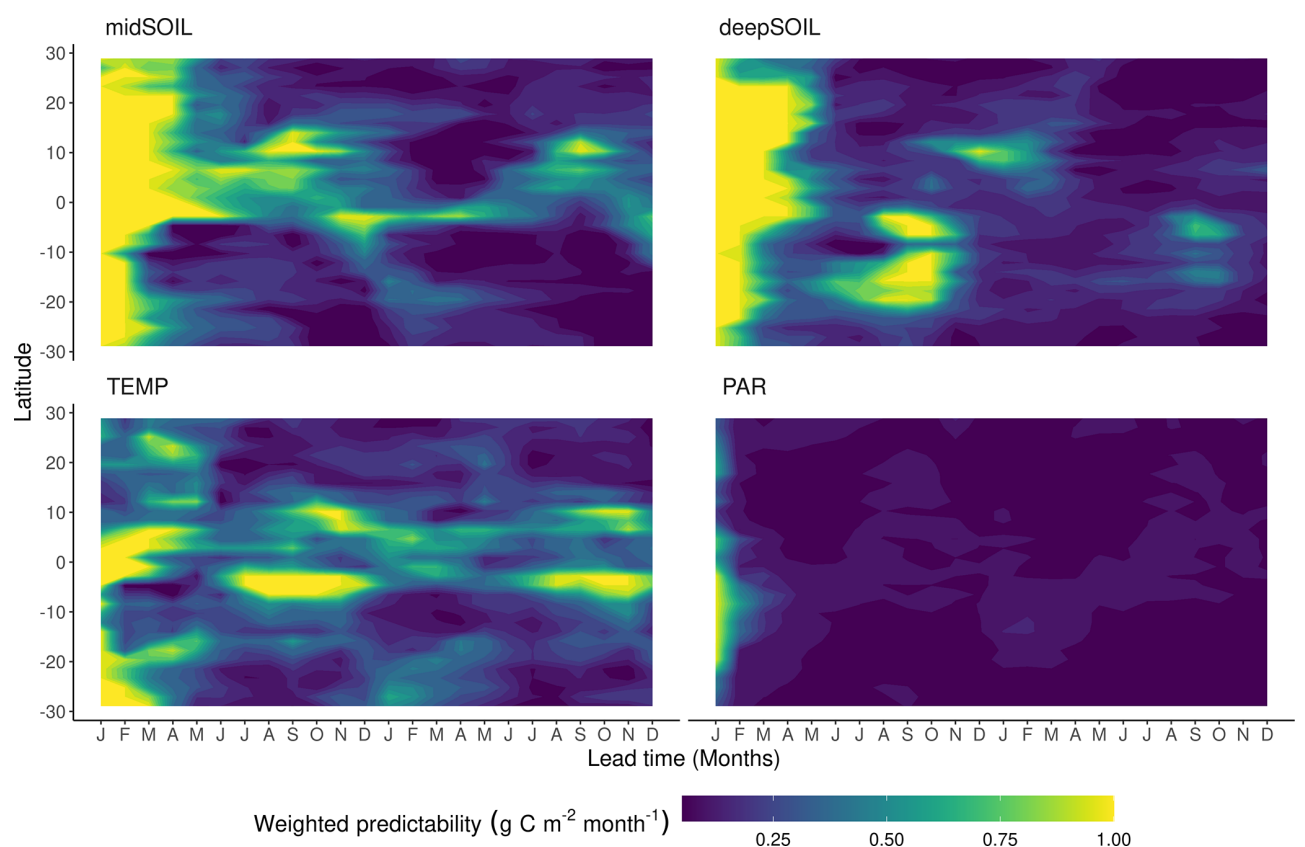

Figure 5. Zonal means of contributing components to the weighted NPP predictability $\left(w V_{\mathrm{c}}\right)$. The contributing components are the predictability of soil moisture at 19-78 and 79-268 cm depth (midSOIL and deepSOIL), air temperature (TEMP), and photosynthetically active radiation (PAR).

modifying function of decomposition to moisture sets $\mathrm{Rh}$ to be more sensible to precipitation in the dry than in the wet season. However, the relationship between $\mathrm{Rh}$ and moisture in the tropics is the highly debated subject of various studies coming to different conclusions. These studies suggest a parabolic or no relationship with soil moisture (Meir et al., 2008) or a linear increase with precipitation (Tian et al., 2000).

\subsubsection{Interannual variability}

Using the distance-based predictability metric $V_{\mathrm{c}}$ also allows us to evaluate the variability of predictability between different initializations. Among the regions with the highest interannual variability of NPPpred are the southern Amazon Basin (box in Fig. 7), with a mean $V_{\mathrm{c}}$ of 0.24 and an SD of 0.32 , and northwestern Australia, with a mean of 0.16 and an SD of $0.60\left(23^{\circ} \mathrm{S}, 122^{\circ} \mathrm{W}\right)$. Figure 7 shows how 


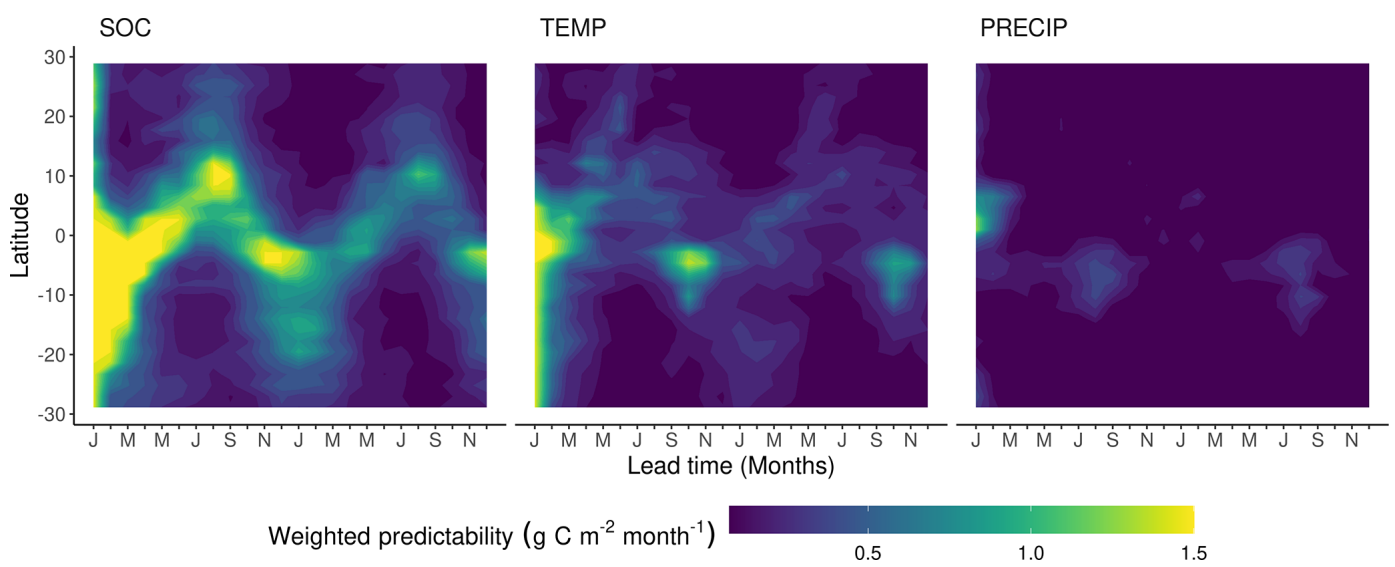

Figure 6. Zonal means of contributing components to the weighted Rh predictability $\left(w V_{\mathrm{c}}\right)$. The contributing components are the predictability of soil organic matter (SOC), air temperature (TEMP), and precipitation (PRECIP).

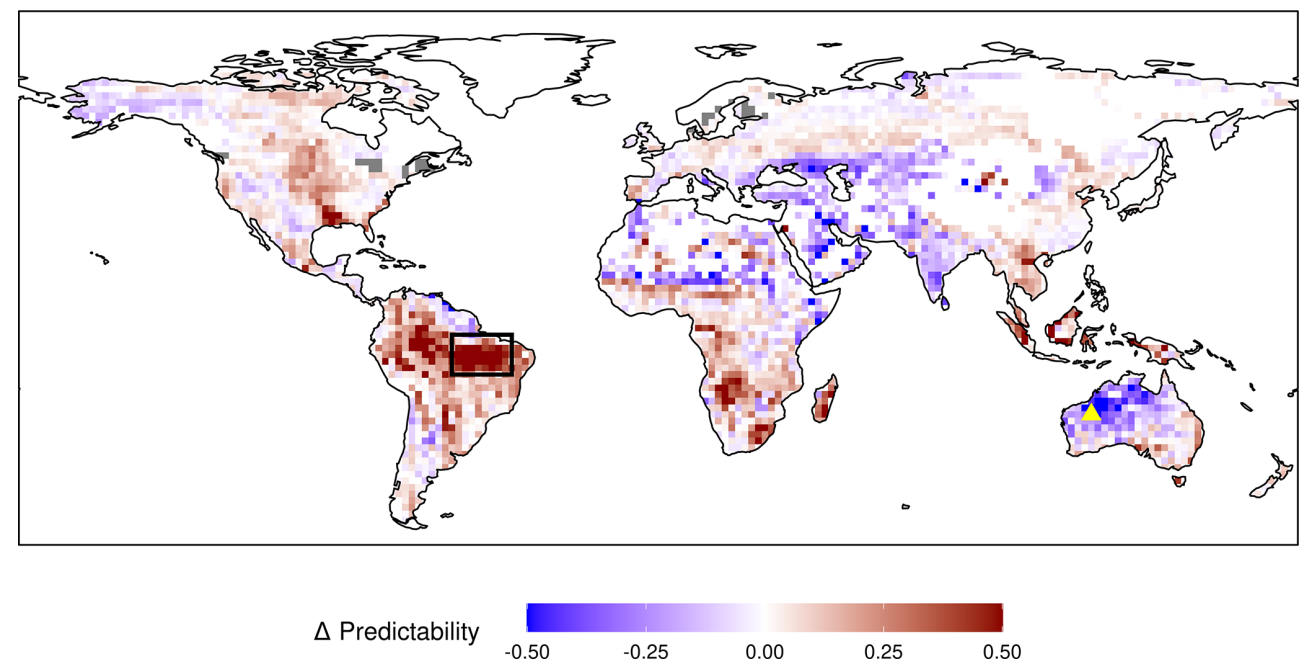

Figure 7. Difference in NPP predictability $\left(V_{\mathrm{c}}\right)$ based on the initial soil moisture. The mean NPP predictability of the first year from the $20 \%$ driest initializations are subtracted from the $20 \%$ wettest initializations for every grid cell. Red colour means higher NPP predictability in wet years and blue colour a higher predictability in dry years. Soil moisture from $19-78 \mathrm{~cm}$ depth is used to determine initial conditions. A large fraction of years included in the initializations are ENSO years, where the initial anomaly is further extended through persisting oceanic forcing. The black box and yellow triangle stand for regions examined in the main text.

the interannual variability of NPPpred is affected by initial soil moisture. The majority of regions with a high NPPpred (Figs. 3 and 4) have a higher predictability in years initiated from wet states. Exceptions to this trend are India and northwestern Australia, where NPPpred is higher in dry years. The strongest difference in NPPpred is in the Amazon Basin, where overall NPPpred and interannual variability of predictability are also at the global maximum.

To determine the mechanisms responsible for this difference in predictability we focus on the composition of the NPPpred in the southern Amazon Basin (box in Fig. 7). To represent wet and dry years, a composite analysis is used based on the ENSO states. (The El Niño years are the dri- est extremes at initialization, while soils are often saturated at the beginning of La Niña years.)

The different composition of NPPpred within the southern Amazon Basin is shown in Fig. 8. La Niña years have an overall higher NPPpred, which even lasts throughout the second year of the simulations. However, the drivers causing the difference in increased La Niña predictability are changing over time. At the start of the growing season, which is between December and July, midSOILpred contributes largely to the increased La Niña predictability, while deepSOILpred gains in importance around June, when topsoils begin to dry out. An increase in TEMPpred explains a large fraction of increased La Niña predictability throughout the first year. 


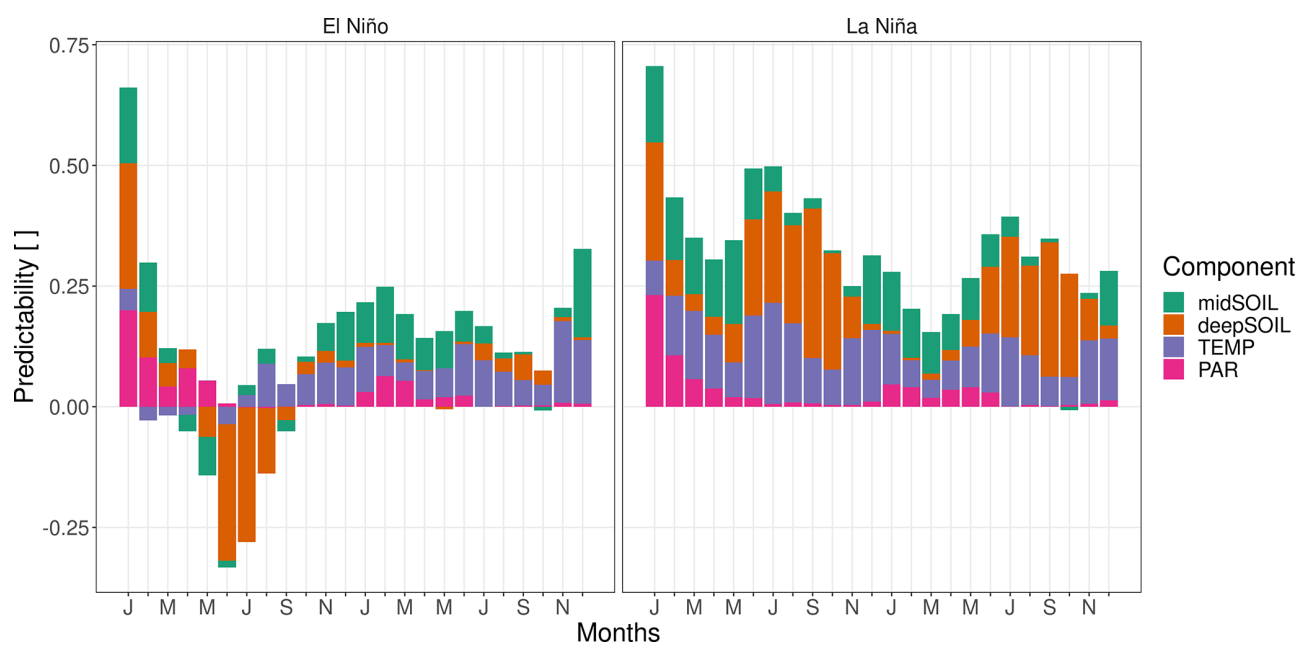

Figure 8. The composition of NPP predictability $\left(V_{\mathrm{c}}\right)$ in the Amazon Basin by ENSO state. The contributing components are the predictability of soil moisture at 19-78 and 79-268 cm depth (midSOIL and deepSOIL), air temperature (TEMP), and photosynthetically active radiation (PAR). La Niña years have an overall higher predictability. Negative values mean an ensemble variance that is exceeding the climatological variance.

(a)

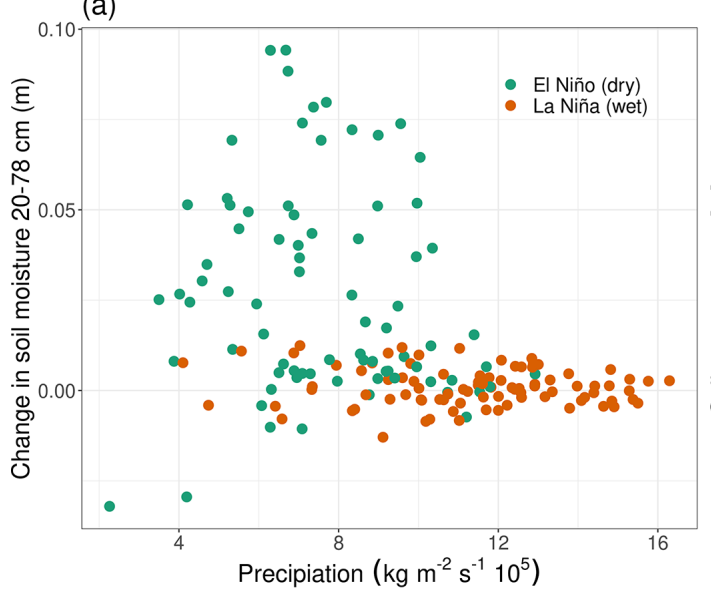

(b)

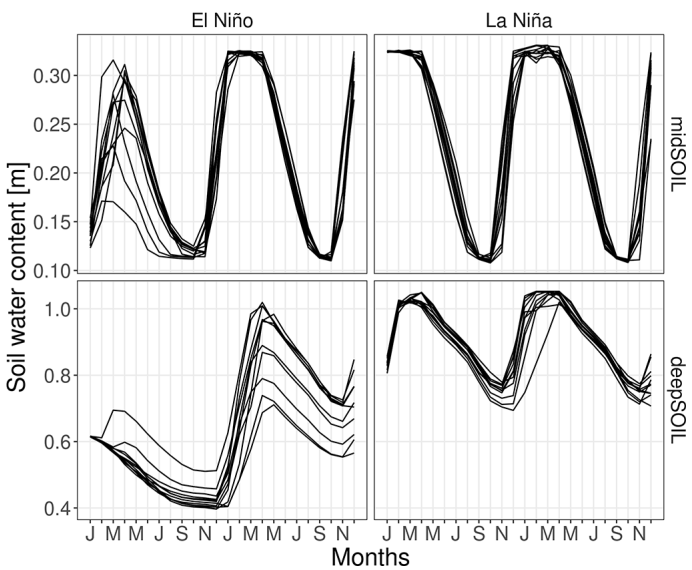

Figure 9. Soil water dynamics of different ENSO states in the Amazon Basin at $8^{\circ} \mathrm{S}, 54^{\circ} \mathrm{W}$. (a) Relationship between February precipitation and change in soil moisture from February to March. (b) Soil water content of the 11-member ensemble simulation for one specific El Niño and La Niña year (midSOIL and deepSOIL are the moisture content at 19-78 and 79-268 cm, respectively).

The increase in midSOILpred during the growing season can be explained by the relationship between precipitation and the change in soil moisture in spring (Fig. 9a). Although the variability of precipitation is comparable between the ENSO states, there is little change in soil moisture in the La Niña years, while the relationship between precipitation and soil moisture change is more pronounced in the El Niño years. The difference in this covariance between the ENSO states is linked to the initial water content (Fig. 9b). The El Niño year is initialized at a depleted state, and precipitation is used to recharge midSOIL. This leads to the translation of the variability in precipitation to a variability in midSOIL. Since midSOIL is saturated at the initialization of the La Niña year, it is hardly affected by the variability of precipitation and the excess water leaves the system as runoff or drainage.

The same mechanism is responsible for the difference in deepSOILpred. As midSOIL dries out during the summer months, NPP is increasingly coupled to deepSOIL. Every ensemble member of the La Niña simulation receives enough precipitation to saturate deepSOIL, thereby reducing its variability, while none of the members in the El Niño year can recharge the soil water deficit.

Increased NPPpred in wet years due to TEMPpred can have multiple reasons which are difficult to disentangle. As soil moisture and surface temperature are coupled through evapotranspiration, a reduced variability in soil moisture suggests a reduced variability in temperature as well. Contribut- 
ing to this effect is the nonlinear mechanism controlling evaporation. At the wet end of the spectrum, evaporation is not limited by soil moisture, meaning that a small variability in soil moisture of a wet soil does not affect evaporation. A counteractive process that might increase predictability in dry years is described by Koster et al. (2011). They suggested that in ecosystems which are generally at the wet end of the spectrum (which is the case for the Amazon Basin) landatmosphere coupling is stronger in dry years when evaporation is limited by soil moisture. This increased coupling can extend TEMPpred by linking it to soil moisture. However, their study was conducted in North America, where landatmosphere coupling is generally stronger than in tropical rainforest (Guo and Dirmeyer, 2013).

To investigate processes behind the difference in temperature variability per ENSO state, we analysed the key elements of the surface energy balance. Almost all processes have a continuously higher variability in the El Niño years (Fig. 10). The strongest difference in variability is in net longwave radiation, but this is most likely an effect of increased variability of surface temperature and not the cause. The SD of net shortwave radiation and ground heat flux are evenly increased by around $0.4 \mathrm{~W} \mathrm{~m}^{-2}$ across the first year. Except for some winter and spring months, the latent and sensible heat fluxes have an increased variability in the El Niño years. At the peak, difference in variability in August is mostly due to an increased variability in the latent heat flux.

As mentioned above, there are also certain regions with an inverse relationship between wetness and NPPpred. These are predominantly in arid regions like northwestern Australia, India, northern Caucasus, and the western US (Fig. 7). The mechanisms explaining the increased NPPpred in dry years are exemplified using two initializations from the dry and wet spectrum in northwestern Australia at $23^{\circ} \mathrm{S}, 122^{\circ} \mathrm{E}$ (yellow triangle in Fig. 7).

This higher NPPpred can be attributed to less variability in deepSOIL and PAR (Fig. 11). The predictabilityproviding mechanism of deepSOIL is comparable with the process in the Amazon Basin. With soil moisture dynamics frequently operating at extreme ends of the water-holding capacity, the variance can be minimized by all ensemble members being pushed against the boundaries of the system. As opposed to the Amazon Basin, in northwestern Australia the ensemble members are clustered at the dry end of the water-holding capacity (Fig. 11a dry years), while any introduction of soil moisture will increase the variability. Another difference in NPPpred is caused by a differing variability of PAR (Fig. 11b). Most dry years have little cloud cover and no restriction of incoming radiation. However, in wet years it is difficult to predict the extent of precipitation and cloud cover, which increases the variability of PAR.

The relationship between initial soil moisture and climate predictability is noted by others. Koster et al. (2011) have determined that, depending on the region, the direction of this relationship can go either way. This asymmetry of predictability is present in areas of high land-atmosphere coupling and is caused by the nonlinear relationship of evaporative fraction with soil moisture. Another study has investigated the predictability of European summer heat and found different weather regime frequencies in initially dry and wet conditions (Quesada et al., 2012). This study adds to the view that predictability is not a mere function of location but depends on the state of the system, and predictability therefore has a strong temporal variability.

\section{Conclusions}

In this study, we take a closer look at spatiotemporal patterns of terrestrial CFpred and identify the climatic and environmental sources of predictability and the feedback mechanisms prolonging the memory of the system. We propose a metric of CFpred weighted by the amplitude of carbon flux anomalies. This metric allows us to evaluate the role of different regions and processes to the predictability of the global carbon cycle.

We find that the spatiotemporal patterns of NPPpred and Rhpred are determined by (a) the predictability of the carbon flux drivers, (b) the climatic anomalies caused by lowfrequency climate modes such as ENSO, (c) the seasonal change in limiting factors, and (d) threshold processes and the nonlinearity of ecosystem responses.

On the global average, NPPpred is explained by SOILpred to $62 \%$ and by TEMPpred to $30 \%$. Rhpred is explained by SOCpred and TEMPpred (50\% and $27 \%$ ) predictability. Decomposing the predictability signal shows there is a high spatiotemporal variability in the drivers of predictability. SOILpred and SOCpred are distributed across all areas of high CFpred, while TEMPpred is mostly to be found in the northern Amazon Basin for CFpred and southern Africa, North America, and Southeast Asia for NPPpred. Rhpred can outlast NPP predictability because SOC, its main driver, has a much higher anomaly persistence than the drivers of NPP. On the other hand, NPP is more directly affected by climatic drivers and is therefore able to benefit from the predictability of persisting climatic anomalies like the effects of ENSO. Intra-annual variability of CFpred is controlled by the seasonally specific limiting factor of NPP and Rh. This leads to NPP gaining predictability in the dry season, when soil moisture replaces PAR as the limiting factor, while Rhpred has its peak in the wet season, when SOC drives the carbon fluxes instead of precipitation in the dry season. This change in limiting factors is due to the nonlinear relationships of transpiration to soil moisture and Rh to precipitation. Both of these relationships describe a saturation point, at which the variability of moisture (precipitation) becomes insignificant to carbon fluxes. Lastly, interannual variability of NPPpred reveals an asymmetry of predictability driven by initial soil moisture and subsequent precipitation. This effect is caused by 


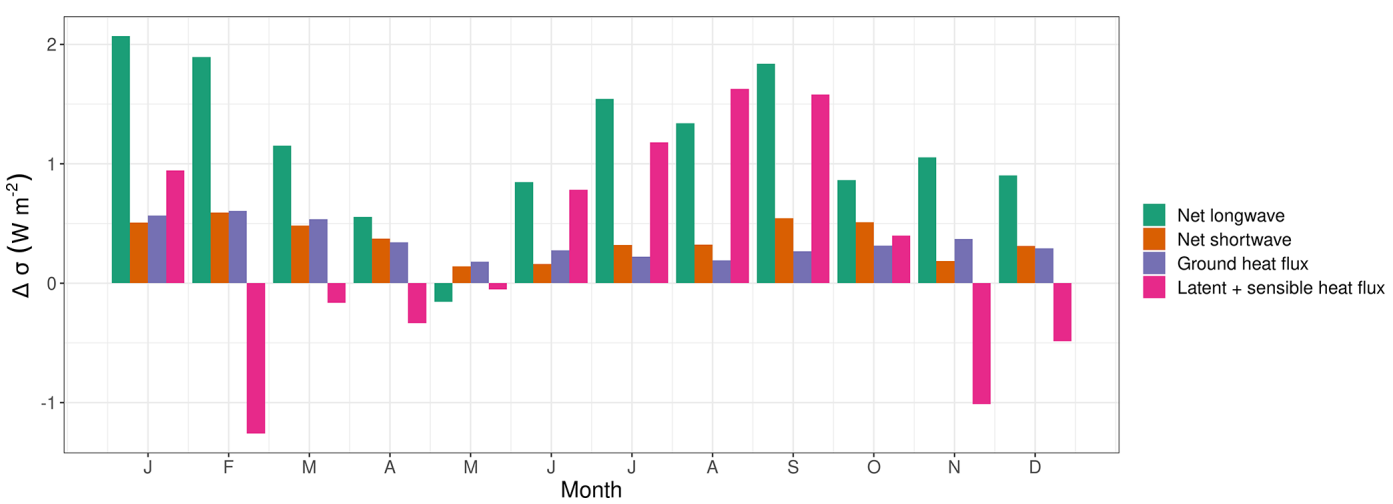

Figure 10. Difference in standard deviation $(\Delta \sigma=\sigma$ El Niño $-\sigma$ La Niña) of different components of the surface energy balance in the Amazon Basin. The latent and sensible heat fluxes are pooled because of their strong negative correlation.

(a)

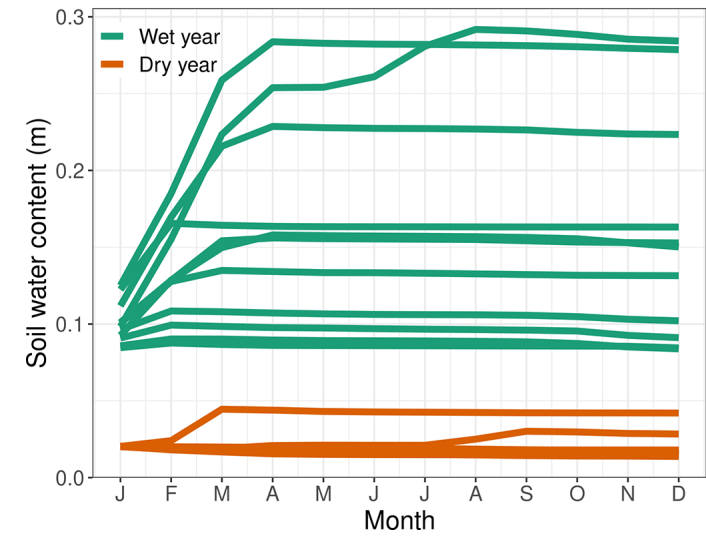

(b)

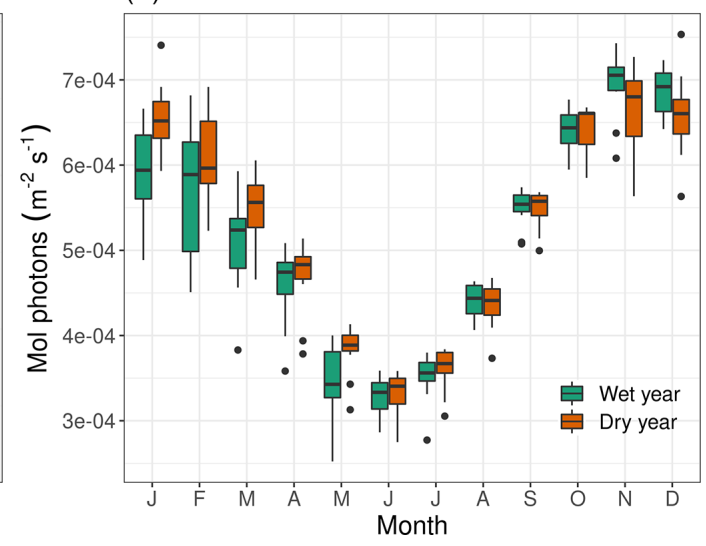

Figure 11. Difference in ensemble member spread in northwestern Australia between a wet and a dry year for (a) deepSOIL and (b) PAR.

ecosystems operating at the boundary conditions of the soil moisture regime. The ensemble members of predominantly wet ecosystems are harmonized in wet years when precipitation exceeds the water-holding capacity and excess water is removed through runoff and drainage. The reverse effect applies for ecosystems operating at the dry end of the spectrum. These processes reduce the covariance between precipitation and NPP.

Our results highlight the sources of CFpred and can be used for model development to improve the representation of the terrestrial carbon cycle. Further research could be directed towards the simulation of the ENSO imprint in climate models and the relationship between soil moisture and terrestrial carbon fluxes.

Code and data availability. The data and scripts to reproduce the this analysis are archived at http://hdl.handle.net/21.11116/ 0000-0009-7256-6 (Dunkl et al., 2021).
Author contributions. ID and VB conceived the study. ID performed the simulations and analysis, created the figures and drafted the manuscript. AS, PF, and VB contributed to manuscript editing and providing feedback.

Competing interests. Some authors are members of the editorial board of Earth System Dynamics. The peer-review process was guided by an independent editor, and the authors have also no other competing interests to declare.

Disclaimer. Publisher's note: Copernicus Publications remains neutral with regard to jurisdictional claims in published maps and institutional affiliations.

Acknowledgements. The authors wish to thank Hongmei Li for her helpful and constructive comments. This paper contributes to the $4 \mathrm{C}$ project. 
Financial support. The article processing charges for this openaccess publication were covered by the Max Planck Society.

Review statement. This paper was edited by Zhenghui Xie and reviewed by two anonymous referees.

\section{References}

Bastos, A., Running, S. W., Gouveia, C., and Trigo, R. M.: The global NPP dependence on ENSO: La Niña and the extraordinary year of 2011, J. Geophys. Res.-Biogeo., 118, 1247-1255, https://doi.org/10.1002/jgrg.20100, 2013.

Bastos, A., Friedlingstein, P., Sitch, S., Chen, C., Mialon, A., Wigneron, J.-P., Arora, V. K., Briggs, P. R., Canadell, J. G., Ciais, P., Chevallier, F., Cheng, L., Delire, C., Haverd, V., Jain, A. K., Joos, F., Kato, E., Lienert, S., Lombardozzi, D., Melton, J. R., Myneni, R., Nabel, J. E. M. S., Pongratz, J., Poulter, B., Rödenbeck, C., Séférian, R., Tian, H., van Eck, C., Viovy, N., Vuichard, N., Walker, A. P., Wiltshire, A., Yang, J., Zaehle, S., Zeng, N., and Zhu, D.: Impact of the 2015/2016 El Niño on the terrestrial carbon cycle constrained by bottom-up and topdown approaches, Philos. T. R. Soc. Lond. B, 373, 20170304 , https://doi.org/10.1098/rstb.2017.0304, 2018.

Becker, E. J., van den Dool, H., and Peña, M.: Short-Term Climate Extremes: Prediction Skill and Predictability, J. Climate, 26, 512-531, https://doi.org/10.1175/JCLI-D-12-00177.1, 2013.

Beer, C., Reichstein, M., Tomelleri, E., Ciais, P., Jung, M., Carvalhais, N., Rodenbeck, C., Arain, M. A., Baldocchi, D., Bonan, G. B., Bondeau, A., Cescatti, A., Lasslop, G., Lindroth, A., Lomas, M., Luyssaert, S., Margolis, H., Oleson, K. W., Roupsard, O., Veenendaal, E., Viovy, N., Williams, C., Woodward, F. I., and Papale, D.: Terrestrial Gross Carbon Dioxide Uptake: Global Distribution and Covariation with Climate, Science, 329, 834838, https://doi.org/10.1126/science.1184984, 2010.

Bellucci, A., Haarsma, R., Bellouin, N., Booth, B., Cagnazzo, C., van den Hurk, B., Keenlyside, N., Koenigk, T., Massonnet, F., Materia, S., and Weiss, M.: Advancements in decadal climate predictability: The role of nonoceanic drivers, Rev. Geophys., 53, 165-202, https://doi.org/10.1002/2014RG000473, 2015.

Betts, R. A., Jones, C. D., Knight, J. R., Keeling, R. F., and Kennedy, J. J.: El Niño and a record $\mathrm{CO}_{2}$ rise, Nature Clim Change, 6, 806810, https://doi.org/10.1038/nclimate3063, 2016.

Bloom, A. A., Exbrayat, J.-F., van der Velde, I. R., Feng, L., and Williams, M.: The decadal state of the terrestrial carbon cycle: Global retrievals of terrestrial carbon allocation, pools, and residence times, P. Natl. Acad. Sci. USA, 113, 1285-1290, https://doi.org/10.1073/pnas.1515160113, 2016.

Boer, G. J., Kharin, V. V., and Merryfield, W. J.: Decadal predictability and forecast skill, Clim. Dynam., 41, 1817-1833, https://doi.org/10.1007/s00382-013-1705-0, 2013.

Chadburn, S. E., Burke, E. J., Cox, P. M., Friedlingstein, P., Hugelius, G., and Westermann, S.: An observationbased constraint on permafrost loss as a function of global warming, Nat. Clim. Change, 7, 340-344, https://doi.org/10.1038/nclimate3262, 2017.

Chikamoto, Y., Timmermann, A., Stevenson, S., DiNezio, P., and Langford, S.: Decadal predictability of soil water, vegetation, and wildfire frequency over North America, Clim. Dynam., 45, 2213-2235, https://doi.org/10.1007/s00382-015-2469-5, 2015.

Ciais, P., Sabine, C., Bala, G., Bopp, L., Brovkin, V., Canadell, J., Chhabra, A., DeFries, R., Galloway, J., Heimann, M., Jones, C., Le Quéré, C., Mynen, R. B., Piao, S., Thornton, P., Ahlström, A., Anav, A., Andrews, O., Archer, D., Arora, V., Bonan, G., Borges, A. V., Bousquet, P., Bouwman, L., Bruhwiler, L. M., Caldeira, K., Cao, L., Chappellaz, J., Chevallier, F., Cleveland, C., Cox, P., Dentener, F. J., Doney, S. C., Erisman, J. W., Euskirchen, E. S., Friedlingstein, P., Gruber, N., Gurney, K., Holland, E. A., Hopwood, B., Houghton, R. A., House, J. I., Houweling, S., Hunter, S., Hurtt, G., Jacobson, A. D., Jain, A., Joos, F., Jungclaus, J., Kaplan, J. O., Kato, E., Keeling, R., Khatiwala, S., Kirschke, S., Goldewijk, K. K., Kloster, S., Koven, C., Kroeze, C., Lamarque, J.-F., Lassey, K., Law, R. M., Lenton, A., Lomas, M. R., Luo, Y., Maki, T., Marland, G., Matthews, H. D., Mayorga, E., Melton, J. R., Metzl, N., Munhoven, G., Niwa, Y., Norby, R. J., O’Connor, F., Orr, J., Park, G.-H., Patra, P., Peregon, A., Peters, W., Peylin, P., Piper, S., Pongratz, J., Poulter, B., Raymond, P. A., Rayner, P., Ridgwell, A., Ringeval, B., Rödenbeck, C., Saunois, M., Schmittner, A., Schuur, E., Sitch, S., Spahni, R., Stocker, B., Takahashi, T., Thompson, R. L., Tjiputra, J., van der Werf, G., van Vuuren, D., Voulgarakis, A., Wania, R., Zaehle, S., and Zeng, N.: Carbon and other biogeochemical cycles, Cambridge University Press, available at: http://www.ipcc.ch/report/ar5/wg1/ (last access: 1 October 2021), 2013.

Coleman, K., Jenkinson, D. S., Crocker, G. J., Grace, P. R., Klír, J., Körschens, M., Poulton, P. R., and Richter, D. D.: Simulating trends in soil organic carbon in long-term experiments using RothC-26.3, Geoderma, 81, 29-44, https://doi.org/10.1016/S0016-7061(97)00079-7, 1997.

Dunkl, I., Spring, A., Friedlingstein, P., and Brovkin, V.: Processbased analysis of terrestrial carbon flux predictability, available at: http://hdl.handle.net/21.11116/0000-0009-7256-6, last access: 20 November 2021.

Collins, M. and Sinha, B.: Predictability of decadal variations in the thermohaline circulation and climate, Geophys. Res. Lett., 30, 1306, https://doi.org/10.1029/2002GL016504, 2003.

Fang, Y., Michalak, A. M., Schwalm, C. R., Huntzinger, D. N., Berry, J. A., Ciais, P., Piao, S., Poulter, B., Fisher, J. B., Cook, R. B., Hayes, D., Huang, M., Ito, A., Jain, A., Lei, H., Lu, C., Mao, J., Parazoo, N. C., Peng, S., Ricciuto, D. M., Shi, X., Tao, B., Tian, H., Wang, W., Wei, Y., and Yang, J.: Global land carbon sink response to temperature and precipitation varies with ENSO phase, Environ. Res. Lett., 12, 064007, https://doi.org/10.1088/1748-9326/aa6e8e, 2017.

Friedlingstein, P., O’Sullivan, M., Jones, M. W., Andrew, R. M., Hauck, J., Olsen, A., Peters, G. P., Peters, W., Pongratz, J., Sitch, S., Le Quéré, C., Canadell, J. G., Ciais, P., Jackson, R. B., Alin, S., Aragão, L. E. O. C., Arneth, A., Arora, V., Bates, N. R., Becker, M., Benoit-Cattin, A., Bittig, H. C., Bopp, L., Bultan, S., Chandra, N., Chevallier, F., Chini, L. P., Evans, W., Florentie, L., Forster, P. M., Gasser, T., Gehlen, M., Gilfillan, D., Gkritzalis, T., Gregor, L., Gruber, N., Harris, I., Hartung, K., Haverd, V., Houghton, R. A., Ilyina, T., Jain, A. K., Joetzjer, E., Kadono, K., Kato, E., Kitidis, V., Korsbakken, J. I., Landschützer, P., Lefèvre, N., Lenton, A., Lienert, S., Liu, Z., Lombardozzi, D., Marland, G., Metzl, N., Munro, D. R., Nabel, J. E. M. S., Nakaoka, S.-I., Niwa, Y., O’Brien, K., Ono, T., Palmer, P. I., Pierrot, D., Poul- 
ter, B., Resplandy, L., Robertson, E., Rödenbeck, C., Schwinger, J., Séférian, R., Skjelvan, I., Smith, A. J. P., Sutton, A. J., Tanhua, T., Tans, P. P., Tian, H., Tilbrook, B., van der Werf, G., Vuichard, N., Walker, A. P., Wanninkhof, R., Watson, A. J., Willis, D., Wiltshire, A. J., Yuan, W., Yue, X., and Zaehle, S.: Global Carbon Budget 2020, Earth Syst. Sci. Data, 12, 32693340, https://doi.org/10.5194/essd-12-3269-2020, 2020.

Griffies, S. M. and Bryan, K.: A predictability study of simulated North Atlantic multidecadal variability, Clim. Dynam., 13, 459487, https://doi.org/10.1007/s003820050177, 1997.

Guo, Z. and Dirmeyer, P. A.: Interannual Variability of LandAtmosphere Coupling Strength, J. Hydrometeorol., 14, 16361646, https://doi.org/10.1175/JHM-D-12-0171.1, 2013.

Hashimoto, H., Nemani, R. R., White, M. A., Jolly, W. M., Piper, S. C., Keeling, C. D., Myneni, R. B., and Running, S. W.: El Niño-Southern Oscillation-induced variability in terrestrial carbon cycling, J. Geophys. Res.-Atmos., 109, D23110, https://doi.org/10.1029/2004JD004959, 2004.

Holmgren, M., Scheffer, M., Ezcurra, E., Gutiérrez, J. R., and Mohren, G. M.: El Niño effects on the dynamics of terrestrial ecosystems, Trends Ecol. Evol., 16, 89-94, https://doi.org/10.1016/S0169-5347(00)02052-8, 2001.

Ilyina, T., Li, H., Spring, A., Müller, W. A., Bopp, L., Chikamoto, M. O., Danabasoglu, G., Dobrynin, M., Dunne, J., Fransner, F., Friedlingstein, P., Lee, W., Lovenduski, N. S., Merryfield, W. J., Mignot, J., Park, J. Y., Séférian, R., Sospedra-Alfonso, R., Watanabe, M., and Yeager, S.: Predictable Variations of the Carbon Sinks and Atmospheric $\mathrm{CO}_{2}$ Growth in a MultiModel Framework, Geophys. Res. Lett., 48, e2020GL090695, https://doi.org/10.1029/2020GL090695, 2021.

Jolliffe, I. T. and Stephenson, D. B.: Forecast Verification: A Practitioner's Guide in Atmospheric Science, John Wiley \& Sons, Chichester, 2nd edn., 2012.

Jones, C. D., Collins, M., Cox, P. M., and Spall, S. A.: The Carbon Cycle Response to ENSO: A Coupled Climate-Carbon Cycle Model Study, J. Climate, 14, 4113-4129, https://doi.org/10.1175/15200442(2001)014<4113:TCCRTE>2.0.CO;2, 2001.

Jung, M., Reichstein, M., Schwalm, C. R., Huntingford, C., Sitch, S., Ahlström, A., Arneth, A., Camps-Valls, G., Ciais, P., Friedlingstein, P., Gans, F., Ichii, K., Jain, A. K., Kato, E., Papale, D., Poulter, B., Raduly, B., Rödenbeck, C., Tramontana, G., Viovy, N., Wang, Y.-P., Weber, U., Zaehle, S., and Zeng, N.: Compensatory water effects link yearly global land $\mathrm{CO}_{2}$ sink changes to temperature, Nature, 541, 516-520, https://doi.org/10.1038/nature20780, 2017.

Koster, R. D., Mahanama, S. P. P., Yamada, T. J., Balsamo, G., Berg, A. A., Boisserie, M., Dirmeyer, P. A., Doblas-Reyes, F. J., Drewitt, G., Gordon, C. T., Guo, Z., Jeong, J.-H., Lee, W.S., Li, Z., Luo, L., Malyshev, S., Merryfield, W. J., Seneviratne, S. I., Stanelle, T., van den Hurk, B. J. J. M., Vitart, F., and Wood, E. F.: The Second Phase of the Global LandAtmosphere Coupling Experiment:: Soil Moisture Contributions to Subseasonal Forecast Skill, J. Hydrometeorol., 12, 805-822, https://doi.org/10.1175/2011JHM1365.1, 2011.

Krull, E. S., Baldock, J. A., and Skjemstad, J. O.: Importance of mechanisms and processes of the stabilisation of soil organic matter for modelling carbon turnover, Funct. Plant Biol., 30, 207-222, https://doi.org/10.1071/fp02085, 2003.
Lovenduski, N. S., Bonan, G. B., Yeager, S. G., Lindsay, K., and Lombardozzi, D. L.: High predictability of terrestrial carbon fluxes from an initialized decadal prediction system, Environ. Res. Lett., 14, 124074, https://doi.org/10.1088/17489326/ab5c55, 2019.

Luo, Y., Keenan, T. F., and Smith, M.: Predictability of the terrestrial carbon cycle, Glob. Change Biol., 21, 1737-1751, https://doi.org/10.1111/gcb.12766, 2015.

Luo, Y., Ahlström, A., Allison, S. D., Batjes, N. H., Brovkin, V., Carvalhais, N., Chappell, A., Ciais, P., Davidson, E. A., Finzi, A., Georgiou, K., Guenet, B., Hararuk, O., Harden, J. W., He, Y., Hopkins, F., Jiang, L., Koven, C., Jackson, R. B., Jones, C. D., Lara, M. J., Liang, J., McGuire, A. D., Parton, W., Peng, C., Randerson, J. T., Salazar, A., Sierra, C. A., Smith, M. J., Tian, H., Todd-Brown, K. E. O., Torn, M., Groenigen, K. J. v., Wang, Y. P., West, T. O., Wei, Y., Wieder, W. R., Xia, J., Xu, X., Xu, X., and Zhou, T.: Toward more realistic projections of soil carbon dynamics by Earth system models, Global Biogeochem. Cy., 30, 40-56, https://doi.org/10.1002/2015GB005239, 2016.

Mauritsen, T., Bader, J., Becker, T., Behrens, J., Bittner, M., Brokopf, R., Brovkin, V., Claussen, M., Crueger, T., Esch, M., Fast, I., Fiedler, S., Fläschner, D., Gayler, V., Giorgetta, M., Goll, D. S., Haak, H., Hagemann, S., Hedemann, C., Hohenegger, C., Ilyina, T., Jahns, T., Jimenéz-de-la-Cuesta, D., Jungclaus, J., Kleinen, T., Kloster, S., Kracher, D., Kinne, S., Kleberg, D. Lasslop, G., Kornblueh, L., Marotzke, J., Matei, D., Meraner, K., Mikolajewicz, U., Modali, K., Möbis, B., Müller, W. A., Nabel, J. E. M. S., Nam, C. C. W., Notz, D., Nyawira, S.-S., Paulsen, H., Peters, K., Pincus, R., Pohlmann, H., Pongratz, J., Popp, M., Raddatz, T. J., Rast, S., Redler, R., Reick, C. H., Rohrschneider, T., Schemann, V., Schmidt, H., Schnur, R., Schulzweida, U., Six, K. D., Stein, L., Stemmler, I., Stevens, B., Storch, J.S. v., Tian, F., Voigt, A., Vrese, P., Wieners, K.-H., Wilkenskjeld, S., Winkler, A., and Roeckner, E.: Developments in the MPIM Earth System Model version 1.2 (MPI-ESM1.2) and Its Response to Increasing $\mathrm{CO}_{2}$, J. Adv. Model. Earth Sy., 11, 998 1038, https://doi.org/10.1029/2018MS001400, 2019.

Meir, P., Metcalfe, D., Costa, A., and Fisher, R.: The fate of assimilated carbon during drought: impacts on respiration in Amazon rainforests, Philos. T. R. Soc. B, 363, 1849-1855, https://doi.org/10.1098/rstb.2007.0021, 2008.

Mullen, K. M. and van Stokkum, I. H. M.: The Lawson-Hanson algorithm for non-negative least squares (NNLS), available at: https://cran.r-project.org/web/packages/nnls/nnls.pdf (last access: 1 October 2021), 2012.

Mystakidis, S., Davin, E. L., Gruber, N., and Seneviratne, S. I.: Constraining future terrestrial carbon cycle projections using observation-based water and carbon flux estimates, Glob. Change Biol., 22, 2198-2215, https://doi.org/10.1111/gcb.13217, 2016.

Quesada, B., Vautard, R., Yiou, P., Hirschi, M., and Seneviratne, S. I.: Asymmetric European summer heat predictability from wet and dry southern winters and springs, Nat. Clim. Change, 2, 736741, https://doi.org/10.1038/nclimate1536, 2012.

Schaefer, K., Denning, A. S., Suits, N., Kaduk, J., Baker, I., Los, S., and Prihodko, L.: Effect of climate on interannual variability of terrestrial $\mathrm{CO}_{2}$ fluxes, Global Biogeochem. Cy., 16, 49-1-49-12, https://doi.org/10.1029/2002GB001928, 2002.

Sitch, S., Friedlingstein, P., Gruber, N., Jones, S. D., MurrayTortarolo, G., Ahlström, A., Doney, S. C., Graven, H., Heinze, 
C., Huntingford, C., Levis, S., Levy, P. E., Lomas, M., Poulter, B., Viovy, N., Zaehle, S., Zeng, N., Arneth, A., Bonan, G., Bopp, L., Canadell, J. G., Chevallier, F., Ciais, P., Ellis, R., Gloor, M., Peylin, P., Piao, S. L., Le Quéré, C., Smith, B., Zhu, Z., and Myneni, R.: Recent trends and drivers of regional sources and sinks of carbon dioxide, Biogeosciences, 12, 653679, https://doi.org/10.5194/bg-12-653-2015, 2015.

Spring, A. and Ilyina, T.: Predictability Horizons in the Global Carbon Cycle Inferred From a Perfect-Model Framework, Geophys. Res. Lett., 47, e2019GL085311, https://doi.org/10.1029/2019GL085311, 2020.

Spring, A., Ilyina, T., and Marotzke, J.: Inherent uncertainty disguises attribution of reduced atmospheric $\mathrm{CO}_{2}$ growth to $\mathrm{CO}_{2}$ emission reductions for up to a decade, Environ. Res. Lett., 15, 114058, https://doi.org/10.1088/1748-9326/abc443, 2020.

Stockmann, U., Adams, M. A., Crawford, J. W., Field, D. J., Henakaarchchi, N., Jenkins, M., Minasny, B., McBratney, A. B., de Remy de Courcelles, V., Singh, K., Wheeler, I., Abbott, L., Angers, D. A., Baldock, J., Bird, M., Brookes, P. C., Chenu, C., Jastrow, J. D., Lal, R., Lehmann, J., O’Donnell, A. G., Parton, W. J., Whitehead, D., and Zimmermann, M.: The knowns, known unknowns and unknowns of sequestration of soil organic carbon, Agr. Ecosyst. Environ., 164, 80-99, https://doi.org/10.1016/j.agee.2012.10.001, 2013.

Séférian, R., Berthet, S., and Chevallier, M.: Assessing the Decadal Predictability of Land and Ocean Carbon Uptake, Geophys. Res. Lett., 45, 2455-2466, https://doi.org/10.1002/2017GL076092, 2018.

Tews, J., Esther, A., Milton, S. J., and Jeltsch, F.: Linking a population model with an ecosystem model: Assessing the impact of land use and climate change on savanna shrub cover dynamics, Ecol. Model., 195, 219-228, https://doi.org/10.1016/j.ecolmodel.2005.11.025, 2006.

Tian, H., Melillo, J. M., Kicklighter, D. W., McGuire, A. D., Iii, J. H., Iii, B. M., and Vörösmarty, C. J.: Climatic and biotic controls on annual carbon storage in Amazonian ecosystems, Global Ecol. Biogeogr., 9, 315-335, https://doi.org/10.1046/j.13652699.2000.00198.x, 2000.

Tuomi, M., Thum, T., Järvinen, H., Fronzek, S., Berg, B., Harmon, M., Trofymow, J. A., Sevanto, S., and Liski, J.: Leaf litter decomposition - Estimates of global variability based on Yasso07 model, Ecol. Model., 220, 3362-3371, https://doi.org/10.1016/j.ecolmodel.2009.05.016, 2009.

Tziolas, N., Tsakiridis, N., Ogen, Y., Kalopesa, E., Ben-Dor, E., Theocharis, J., and Zalidis, G.: An integrated methodology using open soil spectral libraries and Earth Observation data for soil organic carbon estimations in support of soil-related SDGs, Remote Sens. Environ., 244, 111793, https://doi.org/10.1016/j.rse.2020.111793, 2020.

Wang, G., Sun, S., and Mei, R.: Vegetation dynamics contributes to the multi-decadal variability of precipitation in the Amazon region, Geophys. Res. Lett., 38, L19703, https://doi.org/10.1029/2011GL049017, 2011.
Wang, J., Zeng, N., and Wang, M.: Interannual variability of the atmospheric $\mathrm{CO}_{2}$ growth rate: roles of precipitation and temperature, Biogeosciences, 13, 2339-2352, https://doi.org/10.5194/bg-13-2339-2016, 2016.

Wang, Y., Zhao, P., Yu, R., and Rasul, G.: Inter-decadal variability of Tibetan spring vegetation and its associations with eastern China spring rainfall, Int. J. Climatol., 30, 856-865, https://doi.org/10.1002/joc.1939, 2010.

Weiss, M., van den Hurk, B., Haarsma, R., and Hazeleger, W.: Impact of vegetation variability on potential predictability and skill of EC-Earth simulations, Clim. Dynam., 39, 2733-2746, https://doi.org/10.1007/s00382-012-1572-0, 2012.

Weiss, M., Miller, P. A., van den Hurk, B. J. J. M., van Noije, T., Ştefănescu, S., Haarsma, R., van Ulft, L. H., Hazeleger, W., Le Sager, P., Smith, B., and Schurgers, G.: Contribution of Dynamic Vegetation Phenology to Decadal Climate Predictability, J. Climate, 27, 8563-8577, https://doi.org/10.1175/JCLI-D-1300684.1, 2014.

Winkler, A. J., Myneni, R. B., Hannart, A., Sitch, S., Haverd, V., Lombardozzi, D., Arora, V. K., Pongratz, J., Nabel, J. E. M. S., Goll, D. S., Kato, E., Tian, H., Arneth, A., Friedlingstein, P., Jain, A. K., Zaehle, S., and Brovkin, V.: Slowdown of the greening trend in natural vegetation with further rise in atmospheric $\mathrm{CO}_{2}$, Biogeosciences, 18, 4985-5010, https://doi.org/10.5194/bg-184985-2021, 2021.

Xu, X., Schimel, J., Thornton, P. E., Song, X., Yuan, F., and Goswami, S.: Substrate and environmental controls on microbial assimilation of soil organic carbon: a framework for Earth System Models, Ecol. Lett., 17, 547-555, https://doi.org/10.1111/ele.12254, 2014.

Zeng, N., Neelin, J. D., Lau, K. M., and Tucker, C. J.: Enhancement of Interdecadal Climate Variability in the Sahel by Vegetation Interaction, Science, 286, 1537-1540, https://doi.org/10.1126/science.286.5444.1537, 1999.

Zeng, N., Yoon, J.-H., Vintzileos, A., Collatz, G. J., Kalnay, E., Mariotti, A., Kumar, A., Busalacchi, A., and Lord, S.: Dynamical prediction of terrestrial ecosystems and the global carbon cycle: A 25-year hindcast experiment, Global Biogeochem. Cy., 22, GB4015, https://doi.org/10.1029/2008GB003183, 2008.

Zeng, N., Zhao, F., Collatz, G. J., Kalnay, E., Salawitch, R. J., West, T. O., and Guanter, L.: Agricultural Green Revolution as a driver of increasing atmospheric $\mathrm{CO}_{2}$ seasonal amplitude, Nature, 515, 394-397, https://doi.org/10.1038/nature13893, 2014. 